\title{
A FOTOGRAFIA DE ROBERT FRANK NA BUSCA IDENTITÁRIA DO \\ "AMERICAN WAY OF LIFE": \\ A CAPTURA DO "DIFERENTE" POR UM OLHAR ESTRANGEIRO
}

\author{
Anderson Lopes da Silva ${ }^{1}$ \\ Camilla Martins ${ }^{2}$ \\ Raissa Silva Daguer ${ }^{3}$
}

\section{Introdução: o artista, a obra e as influências}

A carreira fotográfica de Robert Frank começa com a ameaça nazista, durante a Segunda Guerra Mundial. Apesar de a família ter ficado segura durante o conflito, o interesse de Frank pela fotografia nasceu da necessidade de expressar os sentimentos guardados no período.

Nascido em Zurique, na Suíça, ele começa a trabalhar lado a lado com designers e outros fotógrafos. Entretanto seu primeiro trabalho significativo foi longe da estética utilizada na rotina profissional. Black and White Things foi o primeiro livro de imagens, feito à mão, com quarenta fotos. Nessa obra, a linguagem única utilizada por Robert Frank, que mais tarde se firmaria com o lançamento de The Americans, começa a se formar.

Muito diferente dos livros de fotografia editados na época, Black and White Things não apresentava início, meio e fim, e muito menos qualquer tipo de moralização. Sem legendas, as fotos deixavam espaço para a interpretação do leitor. Em de suas muitas entrevistas, Frank havia dito que: "É uma sequência que tal como as nossas vidas é ambígua, não há momentos decisivos, (...) o livro é antes uma sequência que revela o equívoco da nossa realidade”. Depois de confecionar seu livro, Frank parte para Nova Iorque, onde começa a trabalhar com fotografia de moda.

Mas cansado de fotografar modelos, sapatos e em estúdios, Frank decide viajar pela América latina (Peru) e Europa (Inglaterra, País de Gales, Espanha e França) e volta aos EUA somente em 1950. É nesse período que começa o trabalho, hoje considerado fundamental para a fotografia do século XX.

Com o apoio do mentor Walker Evans, que retratou a América durante a Grande Depressão de 1929, e de uma bolsa da Guggenheim Foundation, Robert Frank abdica da

\footnotetext{
${ }^{1}$ Universidade Federal do Paraná, Brasil

${ }^{2}$ Pontifícia Universidade Católica do Paraná, Brasil.

${ }^{3}$ Pontifícia Universidade Católica do Paraná, Brasil.
} 
segurança financeira e parte em viagem através dos EUA, entre 1955 e 1956, com a intenção de documentar a vida americana ou o American Way Of Life. Em pleno período de Guerra Fria, esperava-se que Frank retratasse a América com deslumbramento e unidade. Mas o ritmo de vida acelerado do país e a cultura de valorização exagerada do dinheiro fez com que o fotógrafo ficasse frustrado. Em pouco tempo, Frank passou a ver os EUA como um lugar triste e solitário, características que se tornaram evidentes em seu trabalho.

E dessa viagem mais de 28 mil fotos foram tiradas, das quais apenas 83 formaram o livro The Americans. "O clima opressivo criado por Frank em suas fotografias mostrava uma América que nem ele suspeitava existir" (Mascaro In: Mammi e Schwarcz, 2008: 176).

Além de documentar as tensões entre a ideia de otimismo da década de 1950 e a realidade norte-americana, cheia de contrastes como as diferenças entre classes e as conflitos raciais, Frank se tornou um dos principais artistas visuais a documentar a cultura beat. Até mesmo o prefácio de seu livro foi escrito por Jack Kerouac, autor de On The Road.

Fugindo da estética tradicional de enquadramento e foco, Frank captou a ironia que é viver na América pós-guerra. "Imagens simples e potentes, aquelas capazes de desconstruir e reconstruir o mundo". Assim Cristiano Mascaro (2008: 176) descreve o trabalho de Robert Frank, que também se dedicou à direção de vídeo. Ele dirigiu o curta-metragem Pull My Daisy (1959), escrito e narrado por Kerouac e estrelado por Ginsberg e outros poetas. Mas seu filme de maior sucesso foi Cocksucker Blues, um documentário sobre a turnê mundial dos Rolling Stones de 1972.

Uma das maiores influências de Frank, no campo da fotografia, foi seu mentor: o também fotógrafo Walker Evans. Sobre o fato, Geoff Dyer (2008: 15) conta um curioso relato de Frank ao recente colega Evans, por volta dos anos 1950, justificando sua "própria lista, individualíssima, do que gostaria de fotografar":

Uma cidade à noite, uma área de estacionamento, um supermercado, uma rodovia, o homem que possui três carros e que não possui nenhum, o fazendeiro e seus filhos, uma casa nova e uma casa de tábuas tortas, despotismo de gosto, o sonho da grandeza, publicidade, anúncios de neon, o rosto dos líderes, e o rosto de seus seguidores, tanques de gás, agências de correios e quintais [...].

Jed Perl (2008: 290) ressalta, ao destacar a qualidade poética da obra do jovem fotógrafo suíço, que Walker Evans elogiou: "as fotografias de Frank na U.S. Cammera 
Annual de 1958 por sua 'escala e espaço americanos', por seu 'estilo mordaz e instigante"'. Além de Evans, o designer e editor de arte das Harpe's Bazaar, Alexey Brodovitch foi outra grande influência para o fotógrafo. Jonathan Day (2011, p. 20-23, tradução nossa) comenta que Brodovitch contratou Frank para trabalhar na Harpe's após ver seu trabalho 40 photos e que, a partir dali, o fotógrafo começou a avançar por outros caminhos.

Perl (2009: 289-290) ainda levanta algumas análises sobre as fotografias de Robert Frank, relacionando-as a Monet (falando da fotografia de uma barbearia - em 1958 - que cria a ideia de "uma imagem onírica, irreal") e a Nabakov (quando do olhar de Frank sobre o cotidiano de maneira incomum, vendo em autoestradas, parques públicos e motéis fatos "esdrúxulos, um espetáculo"), subentendo que o pintor impressionista francês e o escritor russo, de certa forma, foram inspirações presentes, ainda que vagamente, no trabalho do fotógrafo.

\section{Importância na atualidade: o legado de Frank}

O legado de Robert Frank pode ser comparado ao de outro grande mestre da fotografia: Henri Cartier-Bresson, que juntos e pelo conjunto das imagens, na visão de Cristiano Mascaro (2008: 175), marcaram profundamente a fotografia do século XX. Com sua principal obra (Les Américains/The Americans) e seu ponto de vista peculiar, onde é possível ver os "conflitos internos e existenciais do fotógrafo" impressos à imagem capturada, Frank influenciou e ainda influencia muitos fotógrafos e outros artistas.

Entre muito dos influenciados, quatro nomes se destacam. São eles: os fotógrafos norteamericanos Garry Winogrand (1928-1984), Bruce Davidson (1933), Ed Ruscha (1937-) e Annie Leibovitz (1949-). Garry Winogrand foi contemporâneo do início da trajetória de Frank e esteve sempre ligado à fotografia e urbanidade, sendo chamado pelo crítico, fotógrafo e curador de arte John Szarkowski, como um dos nomes centrais da fotografia de sua geração, por obras como The Animals e Women are beautiful. Da mesma forma, Bruce Davidson conheceu o trabalho de Frank de perto e, por influência de sua obra sobre a busca identitária americana, Davidson também se notabilizou por suas fotografias que exploravam a Nova York e suas diferenças em Brooklyn Gang, The Dwarf, East 100th Street, Subway. 
Miles Orvell (2003: 131, tradução nossa), falando sobre a relação entre fotografia e sociedade, comenta que nas: "Ruas de Davidson nós vemos a tristeza, a determinação, mas não vemos a derrota ou desespero". Relacionando, assim, a influência de Frank em não pecar pelo exagero sentimentalista ou a busca pelo exotismo (esta, uma das características que Robert mais detestava, segundo Mascaro (2008: 175).

Por sua vez, Ed Ruscha apresenta em suas fotografias, pinturas e em seu envolvimento com o movimento Pop Art, nítidas características da influência recebida de Robert Frank. Em Twentysix Gasoline Stations, publicado em 1963, por exemplo, o registro fotográfico de uma América sob o foco dos postos de gasolina, sua representação para a vida dos americanos e a percepção de fatos tidos como incomuns apenas aos olhos de um flâneur, mostram legado de Frank em sua obra. Em março de 2006, durante a exposição "Jeu de paume - 'Ed Ruscha - Photographe”" em Paris, ao ser entrevistado sobre as influências que recebeu, Ruscha confirmou que Evans e Frank foram mais do que importantes em sua trajetória artística.

Já a fotógrafa Annie Leibovitz, a mais recente em relação aos outros artistas influenciados, tem em seu vocabulário iconográfico elementos que configuram a influência de Frank na medida em que ele e Cartie-Bresson eram estimulados a serem "emulados", por assim, dizer nas aulas sobre as principais referências fotográficas no San Francisco Art Institute, onde ela estudava.

Conhecida por seus trabalhos como Photographs, Photographs 19701990, American Olympians, Women, American Music e A Photographer's Life 19902005, Annie (2009: 13, tradução nossa) comenta que ao travar conhecimento com uma nova edição de Les Américains, se apaixonou pela ideia de trabalhar com Frank: "Dirigindo por aí, em um carro, e tirando fotos. Procurando histórias".

A explicação para que o trabalho de Robert Frank tenha tanta reverberação na vida destes e de outros artistas, justifica-se, de acordo com a pesquisadora Gretchen Garner (2003: 162-163), pelo caráter libertário e pela vida beat que o fotógrafo levava. Assim, de determinada maneira, o que fotografava, ele também vivia: "Sobretudo, a clássica paisagem de Frank foi a autoestrada, foi o 'homem na paisagem' que estava dirigindo um carro".

Ela completa dizendo que: "Frank foi um poeta mais triste do que crítico, contudo, houve fotógrafos que o seguiram [...]" e, se o seguiram, foi por verem na figura sagaz e andante de Frank um fotógrafo que buscava uma nova face da identidade americana, uma diferente face que sua câmera compreendia, testemunhava e (por que 
não?) subvertia, ao registrar imagens de uma iconografia americana nem um pouco simplista, caricatural ou mesmo comum.

\section{A teoria das mediações socioculturais: pensando a diferença pela visualidade}

A Teoria das Mediações também oferece seu panorama sobre a presença da diferença como parte da sociedade ao possibilitar um novo olhar metodológico antes impensado à comunicação e as transformações socioculturais. Martín-Barbero escreve sua obra no auge dos pensamentos voltados ao funcionalismo e à Escola de Frankfurt (e, consequentemente, quando termos como indústria cultural, cultura de massa e dominação estavam muito em voga).

Entretanto, na Inglaterra, a Escola de Birmingham e os Estudos Culturais já traziam a grande novidade da época que era justamente pensar de um modo diferente as relações que envolviam os espectadores/consumidores de comunicação (Almeida, 2003: 36). Martín-Barbero tem o seu diferencial em relação aos Estudos Culturais, especificamente por trazer uma nova visão de conceitos sobre nacionalismo, populismo, resistência, "brechas", anarquismo, ressignificação, apropriação e ressemantização no contexto de uma América Latina plural, multidiversa e rica em expressões e manifestações sociais.

A ideia da Teoria das Mediações (Martín-Barbero, 2009) dificilmente pode ser definida por uma frase lacônica ou simplista. Justamente porque trata de questões complexas, como as inter-relações entre comunicação, cultura e hegemonia. Todavia, o que é explícito nesta teoria é o deslocamento metodológico de análise, compreensão e estudo das comunicações pautando-se não nos meios em si, mas sim nas possibilidades de interação causadas por estes e nas mediações culturais, sociais e políticas que fazem parte do convívio e da socialização humana.

Neste contexto, analisar as fotografias de Frank sobre os norte-americanos é um exercício que permite compara as matrizes culturais do país fotografado e as formas de representação exibidas no olhar deste estrangeiro. As mediações socioculturais passam, neste leitura, não apenas pelo viés da fotografia no campo da comunicação, mais, principalmente, pela ideia de projeção e identificação provocada pela obra "Les Américains/The Americans" do artista analisado.

Como metodologia principal, contudo, aqui se faz uso da análise de Leitura de Imagem proposta pelo argentino Alberto Manguel (2001). Neste livro, Manguel passa 
ao largo do vocabulário árduo da crítica e defende a ideia de que os não-especialistas têm o direito de ler imagens como quem lê um texto. $\mathrm{O}$ autor narra histórias que se ocultam em pinturas, esculturas, fotografias e projetos arquitetônicos desde a Roma antiga até as arrojadas experiências da arte do século XX. As obras examinadas vão desde a Roma antiga até o século XX. A vida dos artistas, as anedotas em torno da criação das obras, o percurso das ideias estéticas ao longo dos séculos - tudo isso também faz parte da obra. Aleijadinho, Caravaggio e Picasso, entre outros artistas, têm suas obras lidas por Manguel, assim como o polêmico Monumento do Holocausto também merece a atenção do autor.

\section{Exercício de Leitura I: a imagem como compreensão}

Ao iniciar sua jornada sobre quatro rodas pela América, Robert Frank certamente tinha muitas expectativas em mente sobre o que encontraria e o que realmente daria sentido ao seu trabalho de registro fotográfico. Entretanto, das muitas fotografias publicadas em Les Américains/The Americans, algumas se destacam por trazer o maior símbolo nacional dos Estados Unidos da América: a bandeira, com suas listras vermelhas e brancas (as trezes colônias) e suas 50 estrelas (os seus cinquenta estados), como se estivesse sempre a relembrar aos americanos sua liberdade e independência frente aos colonizadores e ostentando, ao mesmo tempo, seu porte de nação bélica poderosa, gigante econômico e de extensão continental.

Justamente pela presença ora total ora parcial nas imagens de Frank, três de suas fotografias contendo a The Stars and Stripes (ou a Old Glory), como a bandeira americana é chamada, foram escolhidas para um exercício de análise onde o norte direcional está focado na "imagem como compreensão", tal qual Manguel o faz em sua obra Lendo Imagens (2001), contudo, não focando nas artes plásticas.

As fotografias selecionadas são: "Bar”, Detroit (1958), "Fourth of July-Jay”, New York (1958) e "Navy Recruting Station, Post Office-Butte", Montana (1958), todas publicadas na obra Les Américains/The Americans.

A primeira (fig. 1) delas mostra dois quadros e no meio dos dois uma pequena bandeira norteamericana - menor que os quadros - dependurada no alto de um bar em Detroit, na mesma altura que as outras duas imagens. Mesmo sem centralidade em seu foco (o que poderia parecer um erro de paralaxe), a luz que perpassa a bandeira a destaca de tal modo que ela atrai o olhar logo na primeira visualização da foto. Aqui a 
identidade americana, seus líderes e o símbolo máximo estão presentes no mesmo ambiente onde um pequeno "peixe" decorativo aparece.

O bar e seus frequentadores, que não podem ser vistos, parecem estar sendo vistos (vigiados?) pela figura representativa de dois dos maiores presidentes americanos e tendo, como mediador entre os ambos os quadros, a bandeira da nação, a ligação entre todos os americanos.

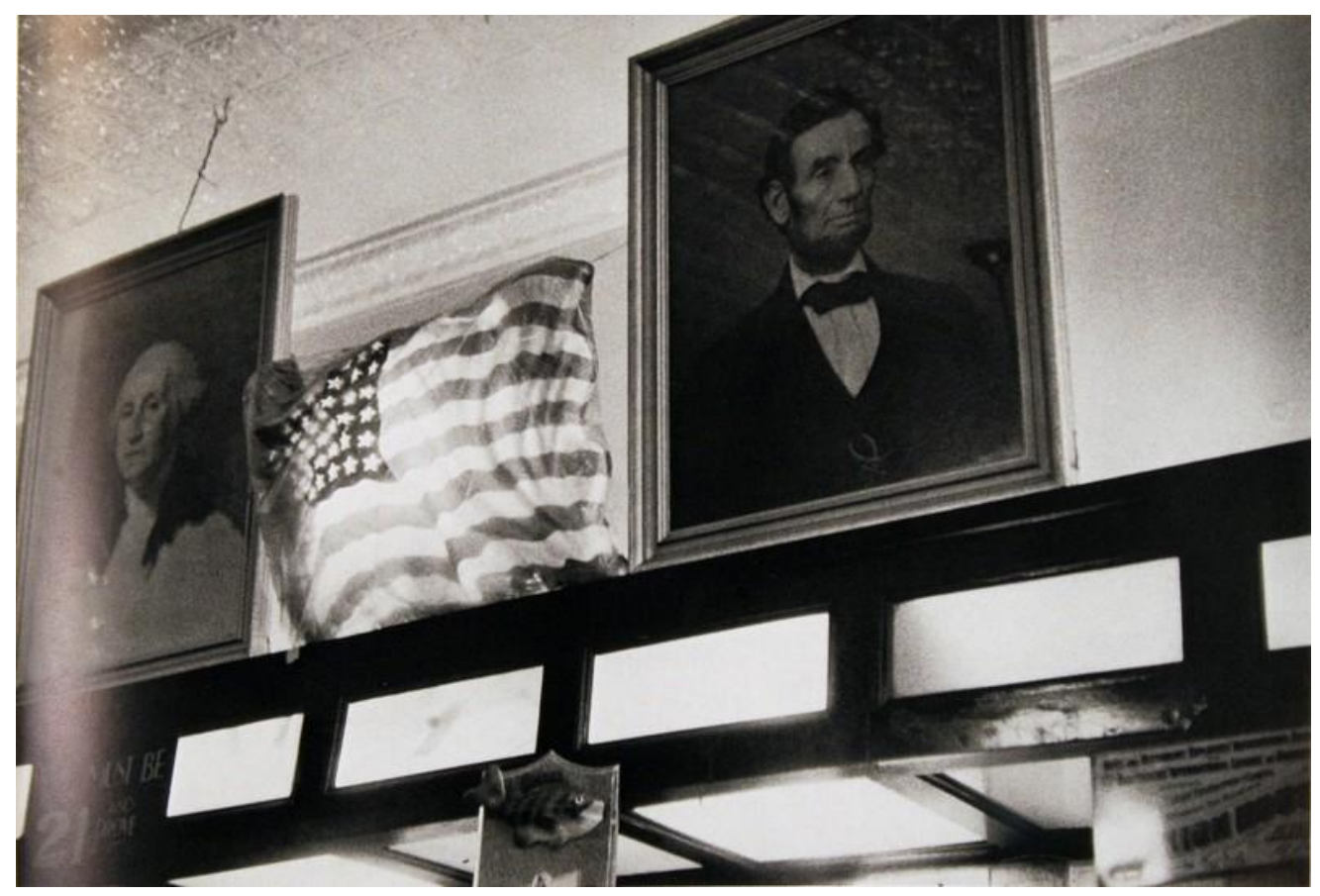

Figura 1 - "Bar", Detroit, (1958) - (C) FRANK, R.

Visão diferenciada se vê na segunda fotografia (fig. 2). Nela o (a) protagonista da cena capturada não são as crianças que brincam as jovens - ao fundo - que passeiam e nem os homens que conversam. Pelo contrário: a protagonista da imagem é justamente aquela a que todos estão alheios, isto é, a grande bandeira americana colocada a céu aberto no Quatro de Julho, em Jay, Nova York. Novamente perpassada pela luz (em menor intensidade que a anterior), é possível ver agora alguns detalhes curiosos só perceptíveis justamente pela presença da bandeira em posição contrária a luz e ao preto e branco da fotografia: há remendos (quatro se destacam) de tamanhos diferenciados em várias partes da Old Glory. Frank parece estar mostrando, como numa alegoria, a imperfeição do american way of life e ao mesmo tempo reforçando a ideia da omissão de erros por parte de uma das maiores potências mundiais (o que levou, de acordo com 
Mascaro (2008: 176) às críticas, ainda na edição em francês, categorizando a obra do fotógrafo como sinistra, perversa e antiamericana).

Ingledew (2005: 87, tradução nossa), analisando a obra de Frank pelo registro quase constante da bandeira americana, afirma que as fotos do fotógrafo expressam: "tristeza, alienação e desnorteamento [...]". E completa: "Frank capturou perfeitamente uma nação no limite entre um otimismo dos anos 1950 que morria e as mudanças radicais que chegavam com os anos 1960".

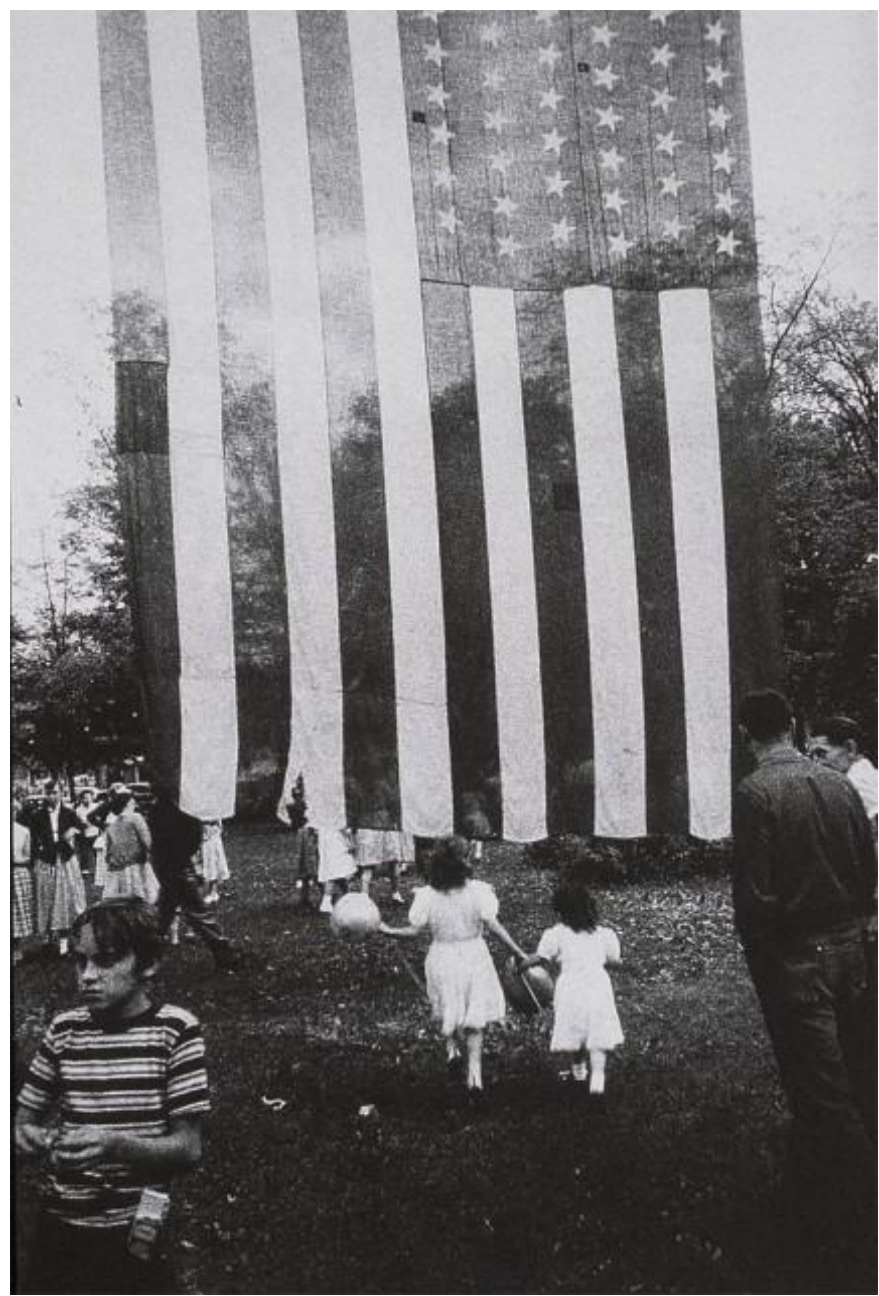

Figura 2 - "Fourth of July-Jay", New York (1958). @ FRANK, R.

A última imagem (fig. 3) em análise mostra - com a câmera posicionada do lado de fora - parcialmente o interior de um centro de Recrutamento da Marinha em Montana. Aparecendo apenas os pés sobre a escrivaninha, é possível imaginar a autoridade que ali estava de modo contemplativo, à vontade, talvez até dormindo no ambiente de trabalho. $\mathrm{O}$ destaque desta foto já não é mais a bandeira americana, que 
aparece no canto direito superior, já que os pés do indivíduo ocupam o ponto de vista central da fotografia, um ponto de fuga.

Aqui, em relação à primeira fotografia analisada, os papéis de vigilância são o oposto: é o espectador (e, por conseguinte, o fotógrafo) que tem este olhar de voyeur para com a autoridade que, pressupõe-se, deveria estar exercendo o papel de proteção dos cidadãos, de vigilância. Mas o que se vê é o contrário: a lei americana tira um cochilo enquanto é observada por nós e pela sisuda bandeira presente na sala. Esta sensação de voyeur, no pensamento de Ingledew (2005: 87, tradução nossa) faz com que você veja as fotografias de um modo cúmplice ao do fotógrafo. Faz com que: "Você se sinta com se estivesse viajando com Frank, olhando pela janela do carro dele".

Fazendo um comparativo com a leitura que Manguel (2001: 107-137) realiza, ao analisar as pinturas da artista italiana Lavinia Fontana, datadas do século XIV, o conceito de compreensão pela imagem se dá na medida em que o artista imprime na tela ou na fotografia, como é o caso, elementos que fornecem ferramentas ao espectador para entender algo que lhe é estranho, ainda não visto (como o exemplo da pintura de Fontana mostrando Retrato de Tognina Gonsalvus, a garotinha que possui a doença hypertrichosis universalis congenita - uma anormalidade que faz com que o rosto e as mãos, em alguns casos, fiquem cobertos de pelos).

Neste caso, o estranho e diferente para Frank é esta face dos EUA, que ele percorre descobrindo e tentando compreender por meio da captura de imagens. Uma face tão diferente e estranha que os próprios americanos se negavam a ver. Mas que o fotógrafo observa e transparece tais questões em suas imagens fazendo com que o espectador também se depare e questione-se. 


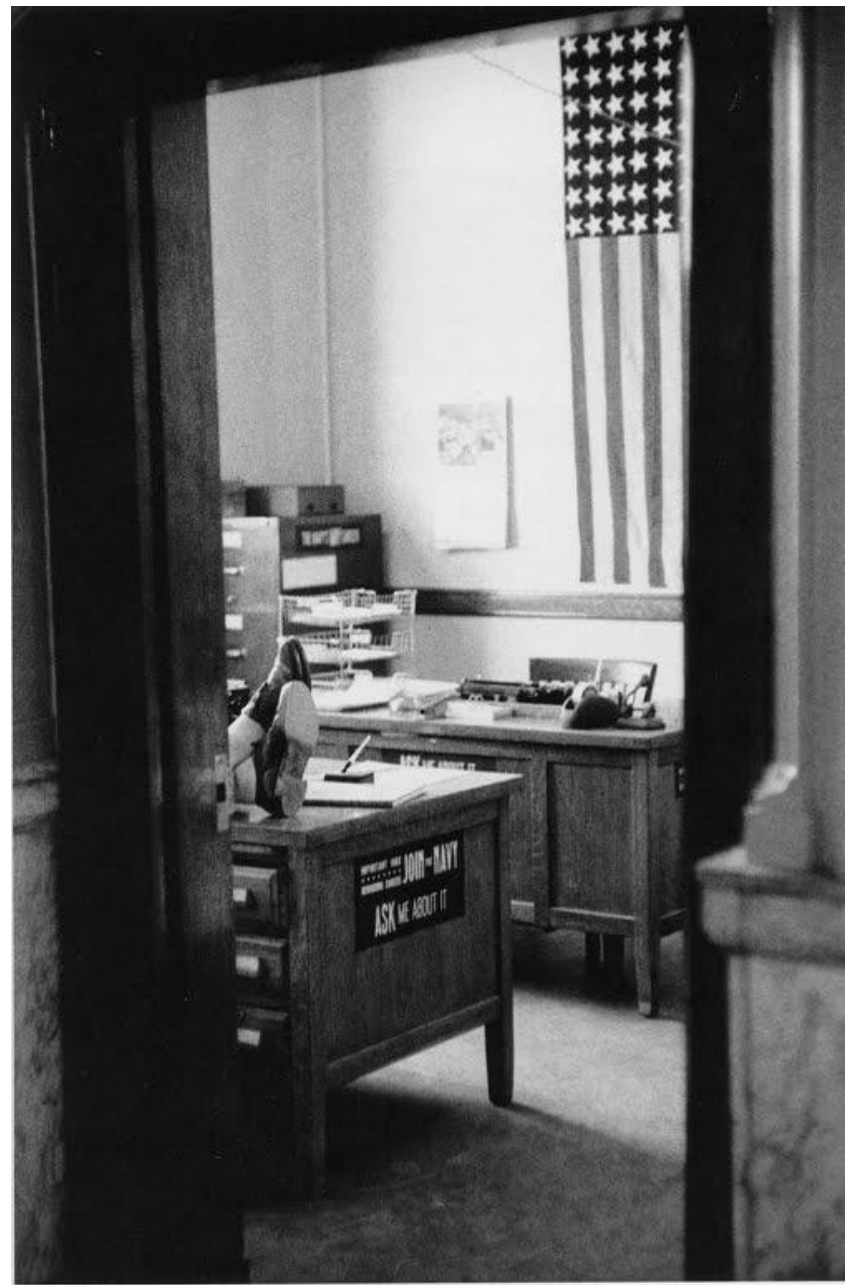

Figura 3 - "Navy Recruting Station, Post Office-Butte", Montana (1958). C FRANK, R.

E isso, na época de publicação, ocorria num contexto histórico, político, social e cultural em que a identidade americana era projetada para o mundo - que até então conhecia os EUA apenas pelos filmes hollywoodianos, pela riqueza econômica ou a nação capitalista poderosa e perfeita.

Manguel (2001: 114), apresenta a obra de Lavinia Fontana como a artista que queria compreender e levar à compreensão dos outros o lado inumano do indivíduo, um rosto onde os pelos já não deixavam muito nítidos as diferenças entre o humano (civilizado) e animal (selvagem). Frank buscava compreender a identidade americana pelo viés contrário: buscar entender o humano, os lugares comuns onde viviam, comiam, se divertiam, para a partir daí traçar um discurso identitário e compreensivo do povo americano (relacionando, às vezes, a dualidade indivíduo e massa).

Mesmo que fosse preciso expor os pontos obscuros da nação com suas mazelas e defeitos. Robert Frank, como Fontana, deixa claro em The Americans que: "O aberrante 
não precisa se esconder, o ser social não precisa fingir, o lado claro e o lado escuro podem se expor a céu aberto" (Manguel, 2001: 137).

Sua busca identitária pela vida americana é sua visão peculiar do mundo, como Wells (2004: 100, tradução nossa) explica ao dizer que: "Em sua coleção de fotos em The Americans, Frank oferece sua própria visão da vida americana na qual ele evitou os temas habituais de investigação documental; nos apresentado, ao invés disso, imagens frescas e irônicas dos momentos fugazes da vida comum".

\section{Exercício de Leitura II: a imagem como testemunho}

Essa análise pretende relacionar a visão de imagem como testemunho, proposta por Manguel, em seu livro Lendo Imagens, com a definição da fotografia como um índice, de Dubois, em O Ato Fotográfico. No capítulo "Imagem como testemunho", Manguel utiliza a fotógrafa Tina Modotti para expor seu pensamento. A imagem fotográfica como um testemunho de acontecimentos: a guerra, terras estrangeiras, o rosto de familiares, entre outros. Apesar dessa visão, parecida com a ideia de fotografia no século XIX, como uma reprodução fiel da realidade, Manguel nos mostra, através do exemplo de Tina, que:

\footnotetext{
Ao contrário da fotografia, o mundo não tem moldura: o olho humano divaga e pode apreender aquilo que está além das margens. Conhecemos os limites de um documento fotográfico, sabemos que ele mostra apenas aquilo que o fotografo quis enquadrar e aquilo que determina luz e sombra lhe permitiram revelar (...) (Manguel, 2001: 92)
}

As fotos de Modotti retratando a realidade da população mexicana, com mãos de um trabalhador, camponesas, crianças tristes, pessoas imundas, mostram uma realidade com a assinatura da fotógrafa, que durante sua vida foi totalmente envolvida com ações sociais, políticas e chegou a trabalhar para uma versão comunista da Cruz Vermelha. Ela própria diz que seu propósito artístico era transformar o tangível em intangível, transmutar a matéria em ideologia. Deste modo, o testemunho parece se encaixar perfeitamente, bem como a ideia da fotografia como índice proposta por Dubois a partir dos estudos de semiótica de Peirce em O Ato Fotográfico. De acordo com Peirce, o índice é uma parte de um todo, um indício de que há algo não visto, não explícito, mas que talvez possamos identificar de acordo com nossa experiência subjetiva ou contexto cultural. Por exemplo, onde há fumaça, há fogo. Para Dubois, a fotografia antes de tudo 
é um índice e somente depois ela pode tornar-se ícone (parecida com a realidade) e adquirir sentido (símbolo).

As fotos de Frank escolhidas para essa análise da imagem como testemunho podem exercer essa função de apenas mostrar a realidade, de um testemunho fiel, e aí talvez possa surgir o questionamento da intenção do artista, que diferente da Tina Modotti, não era engajado em nenhum movimento social ou político. O não visto nas fotos de Frank, o índice, juntamente com o contexto social adquire sentido e aí é que está relevância de toda a sua obra.

As fotografias aqui em questão têm o universo automobilístico como ligação. Um dos símbolos do American Way of Life, por causa da ascensão do modelo de produção em série, conhecido como fordismo, o automóvel estava presente na vida dos americanos como a água ou qualquer outro elemento essencial. A fotografia Santa Fé (fig. 4), de Frank, mostra bombas de um posto de combustível na beira da estrada e uma placa com a palavra SAVE, e parece colocar aquelas bombas como se fossem pessoas que estavam à margem, esperando que alguém visualizasse aquele pedido de ajuda. Entendendo o contexto Guerra Fria e do American Dream, sabemos por agora que a prosperidade e a abundância não chegavam a todos os americanos, principalmente para os negros, imigrantes e àqueles que moravam em regiões distantes dos grandes centros urbanos.

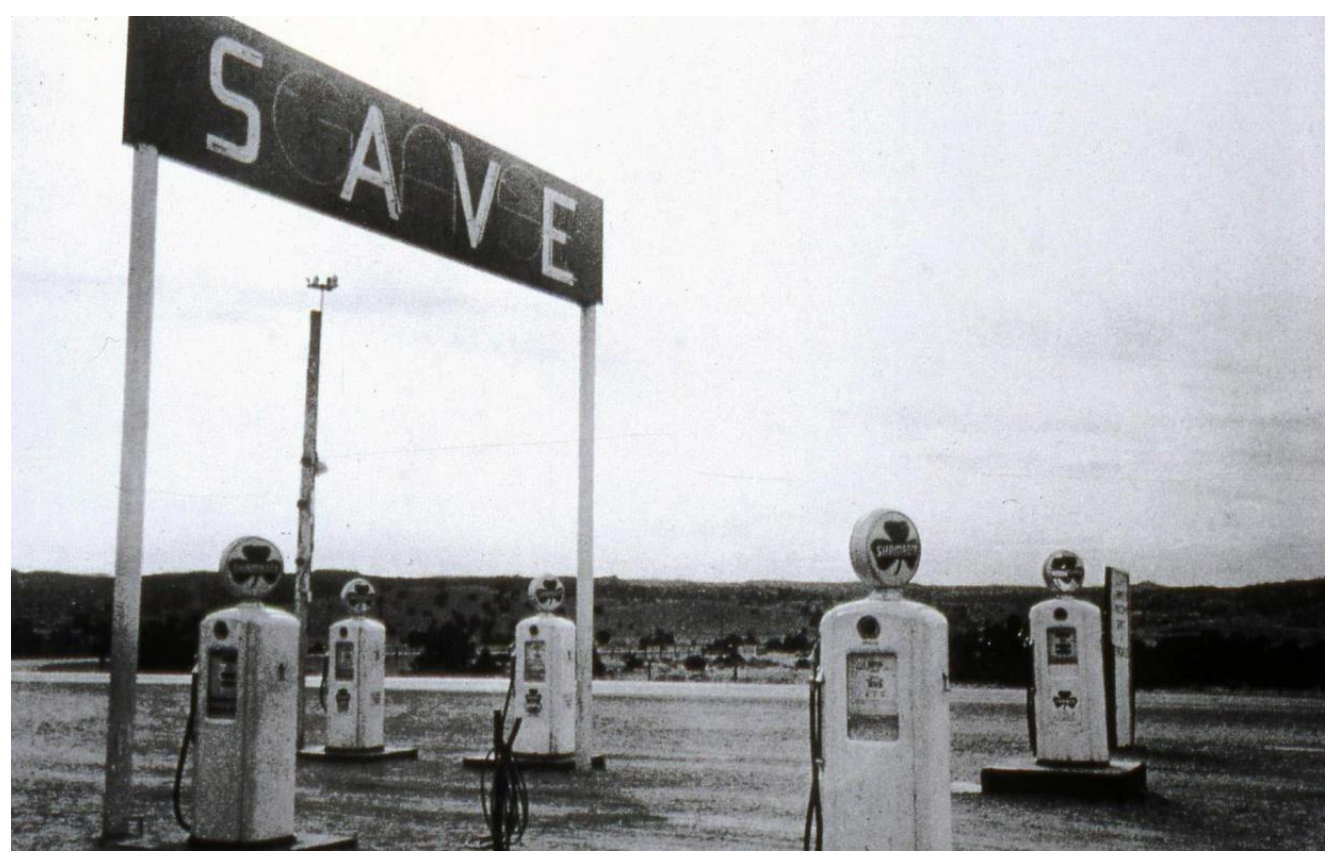

Figura 4 - "Save", Santa Fe, New Mexico" (1956).@ FRANK, R. 
Nesse ponto de vista, a fotografia pode retratar exatamente essa população marginalizada, o posto parece estar num lugar abandonado, esquecido, não há nenhum carro ou pessoa por ali e esse próprio abandono parece ter criado a placa com as letras que formam a palavra SAVE, já que isso só aconteceu porque as demais letras da tal placa caíram, provavelmente pela ação do tempo e desse abandono. Em Car Covered, a imagem (fig. 5) do carro coberto embaixo das palmeiras transmite um ar de mistério, como se aquela capa escondesse algo, que sabemos que é um carro, mas pode ser vista como um reflexo da própria realidade americana não mostrada, não assumida. Além disso, passa a ideia da valorização do bem material, como se o carro merecesse todo esse cuidado, em ser protegido pela capa, em estar "repousando" na sombra das árvores.

Ao mesmo tempo em que a imagem aponta esse cuidado e essa valorização, o fundo parece não condizer com essa leitura, pois não aparenta ser nada luxuoso, possibilitando a interpretação de contraste de que a prosperidade não existe para todos. A terceira fotografia (fig. 6) analisada, Car Accident, finaliza esse pensamento com a ideia de efêmero. As pessoas ali não parecem estar chocadas com o corpo estendido no chão, apesar de estarem em grupo, a foto demonstra um certo distanciamento. Algumas das características já apontadas no restante da obra do fotógrafo. 


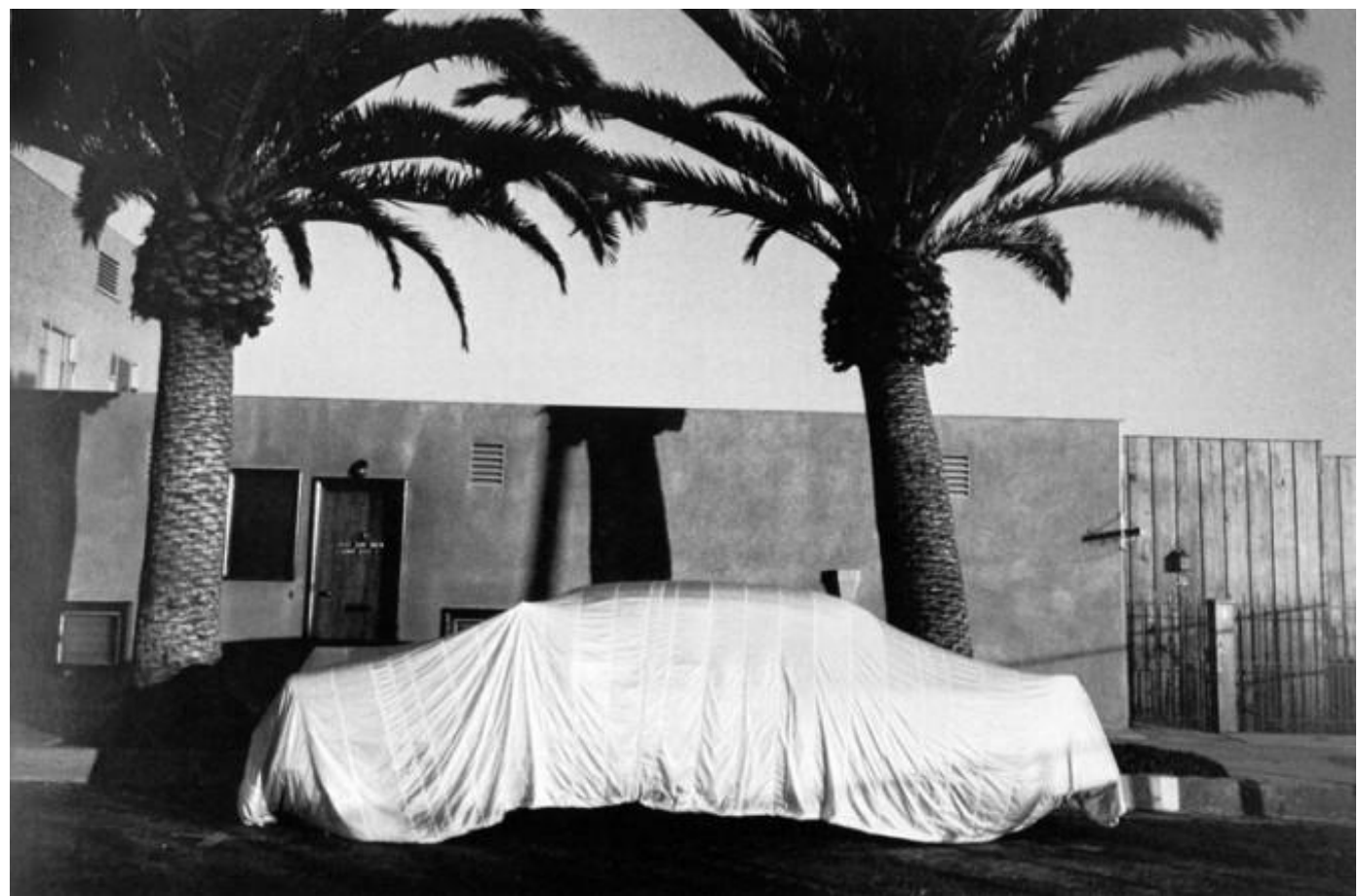

Figura 5 - "Covered Car", Long Beach, California, (1956). C FRANK, R.

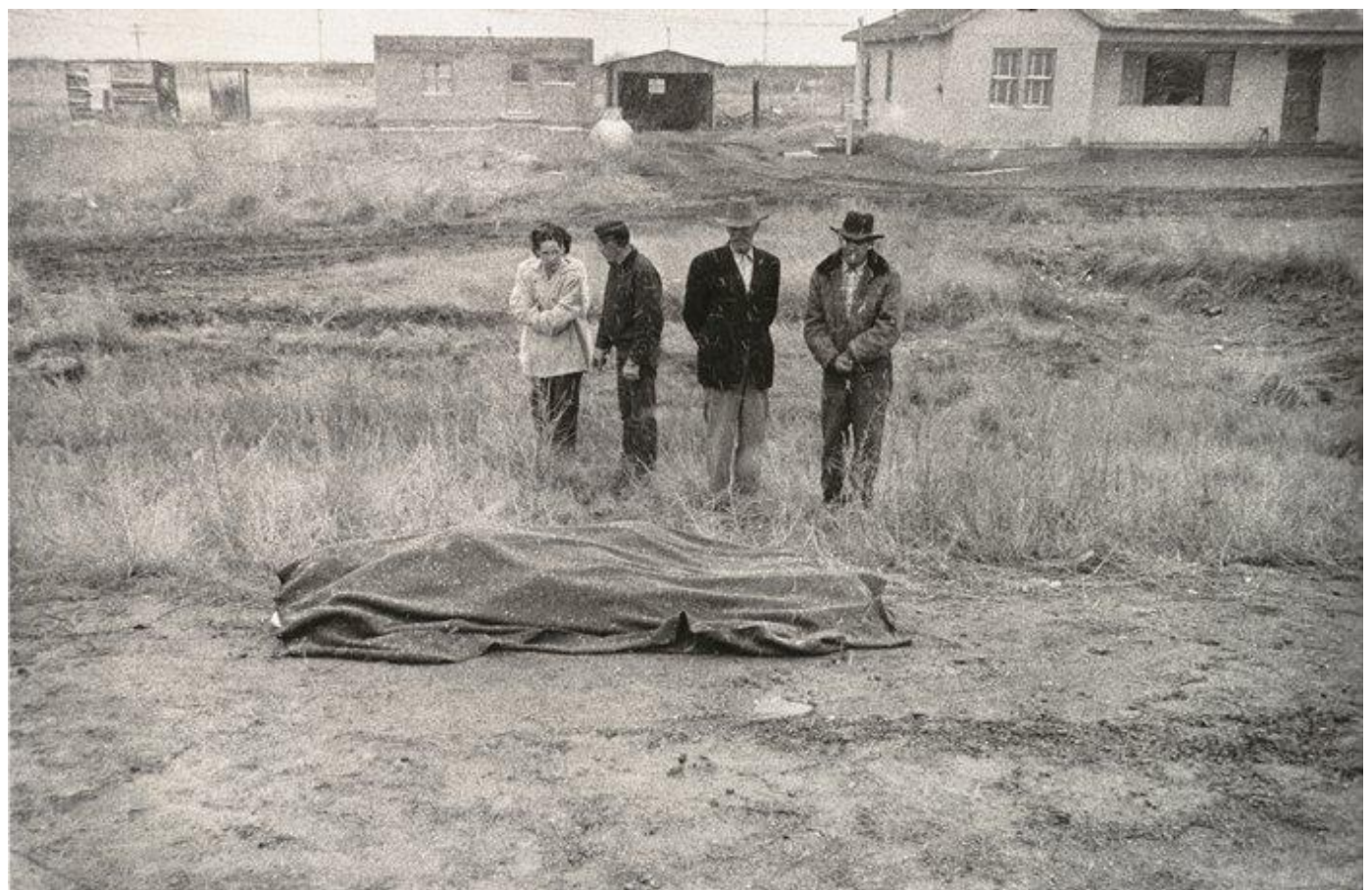

Figura 6 - "Car accident", U.S. 66, between Winslow and Flagstaff, Arizona (1956). (C) FRANK, R. 


\section{Exercício de Leitura III: a imagem como subversão}

Cruas e dinâmicas, as imagens de Frank chegam a puxar o espectador para uma realidade que muitos americanos se recusavam a ver. Tensões raciais, políticas, diferenças sociais e econômicas, a solidão mostrada em rostos perdidos nas ruas e desfiles militares.

As fotografias de Frank contrastavam com o otimismo que os norte americanos queriam demonstrar nos anos 1950. As imagens desfocadas, fotografias de estradas e o senso de composição do artista proporcionavam a quem estivesse vendo suas obras, uma sensação de inquietude, de movimento constante. Indiferente à estética de seus antigos trabalhos no mundo da moda, a América de Frank era repleta de contradições e ambiguidade.

O objetivo de suas fotos não era chocar a sociedade, mas fazer a América ser vista com outros olhos, com os seus olhos. Todo mundo conhecia jukeboxes, motéis de beira de estrada, motocicletas e carros estilosos. Mas ninguém tinha aceitado esses fatos como a base iconográfica daquela época.

Porque o que Frank queria retratar não era necessariamente um povo sem rosto, sem representação, mas um povo sem mente, sem pensamento próprio. Robert Frank conseguiu ilustrar a solidão presente no American way of life. Uma foto (fig. 7) que mostra o patriotismo solitário e cego dos americanos é a do tocador de tuba (intitulada Political Rally, Chicago - 1956), onde um homem aparece sem rosto, completamente coberto pelo instrumento.

Muitos também interpretam essa foto como se a tuba fosse fruto do próprio corpo do homem, tendo suplantado sua cabeça humana. Essa foto retrata um povo que, ao invés de possuir voz e ideias próprias, é comandado a tocar apenas a melodia demandada pela pátria.

Contra a parede, o tocador de tuba está entre uma mulher e um homem, ambos também sem rosto e fragmentados, distantes dele. Marjorie Perloff (2002) afirma que:

Nas imagens de Frank, as pessoas estão sozinhas, em dupla, trio, ou em grupo, mas sempre parecendo curiosamente distantes umas das outras. (...) O foco não está na individualidade, mas no relacionamento com os outros e com a sua cultura. (Perloff, tradução nossa) 


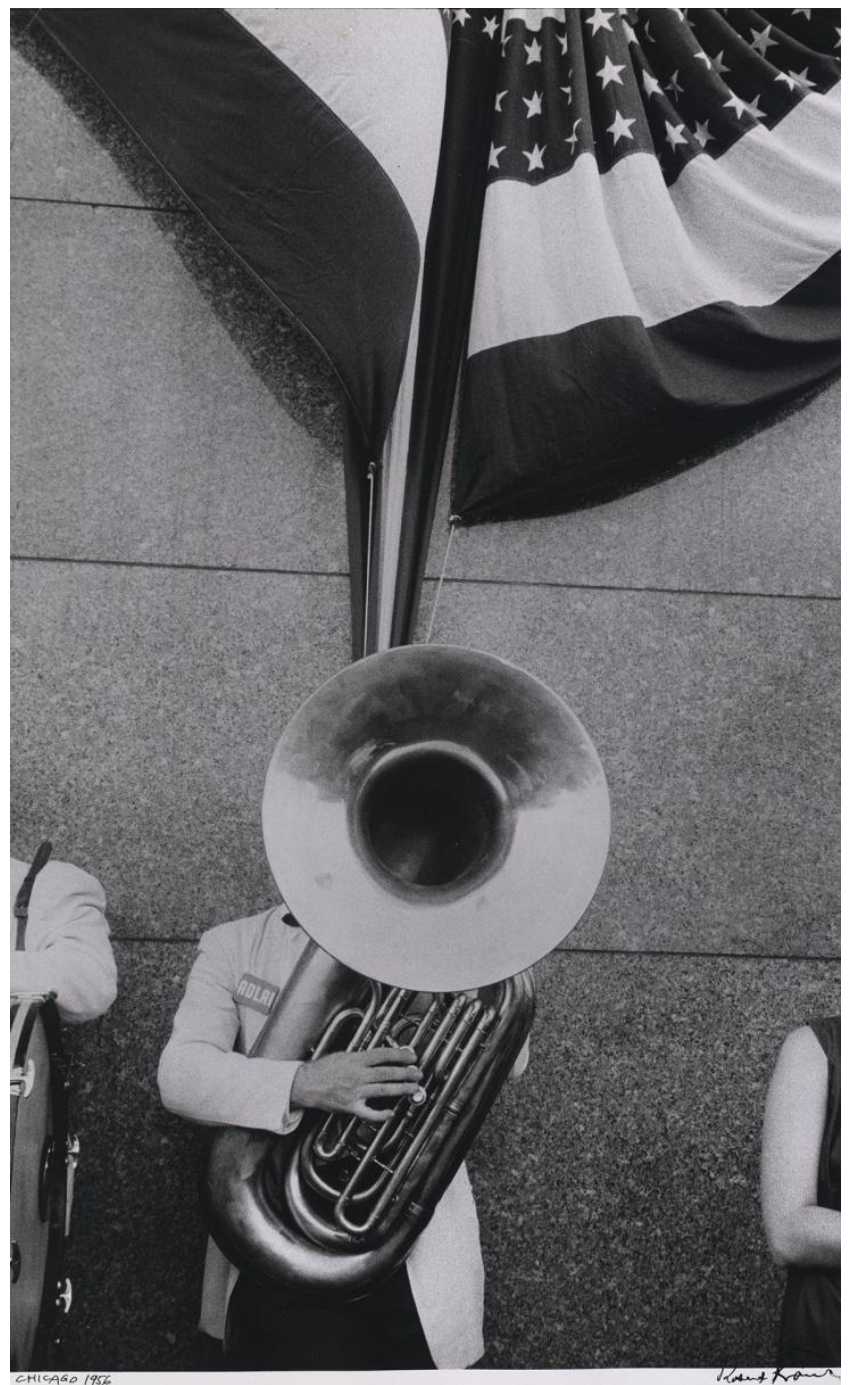

Figura 7 - "Political Rally", Chicago (1956). C FRANK, R.

A foto personifica a alienação e o isolamento por baixo da América de Eisenhower, que objetivava passar a imagem de prosperidade no período pós-guerra. $\mathrm{E}$ algo parecido pode ser dito sobre a primeira foto a ilustrar o livro The Americans, de Robert Frank. Na foto (fig. 8) Parade--Hoboken, New Jersey, o fotógrafo posiciona o espectador em frente a duas janelas. Nessa fotografia, o foco não é o que é visto - e metaforizado - para fora das janelas, mas as pessoas que estão dentro do prédio e o que elas estão vendo.

Pela bandeira hasteada, permite-se entender que os residentes de Hoboken estão vendo algum evento ligado ao patriotismo estadunidense, como Dia dos Veteranos ou algo parecido. E ao ser analisada mais de perto, a fotografia de Frank transforma-se quase em protesto, pois o que interessa capturar é a expressão dos americanos tristes que formam o plano de fundo de um espetáculo patriótico cansado. 


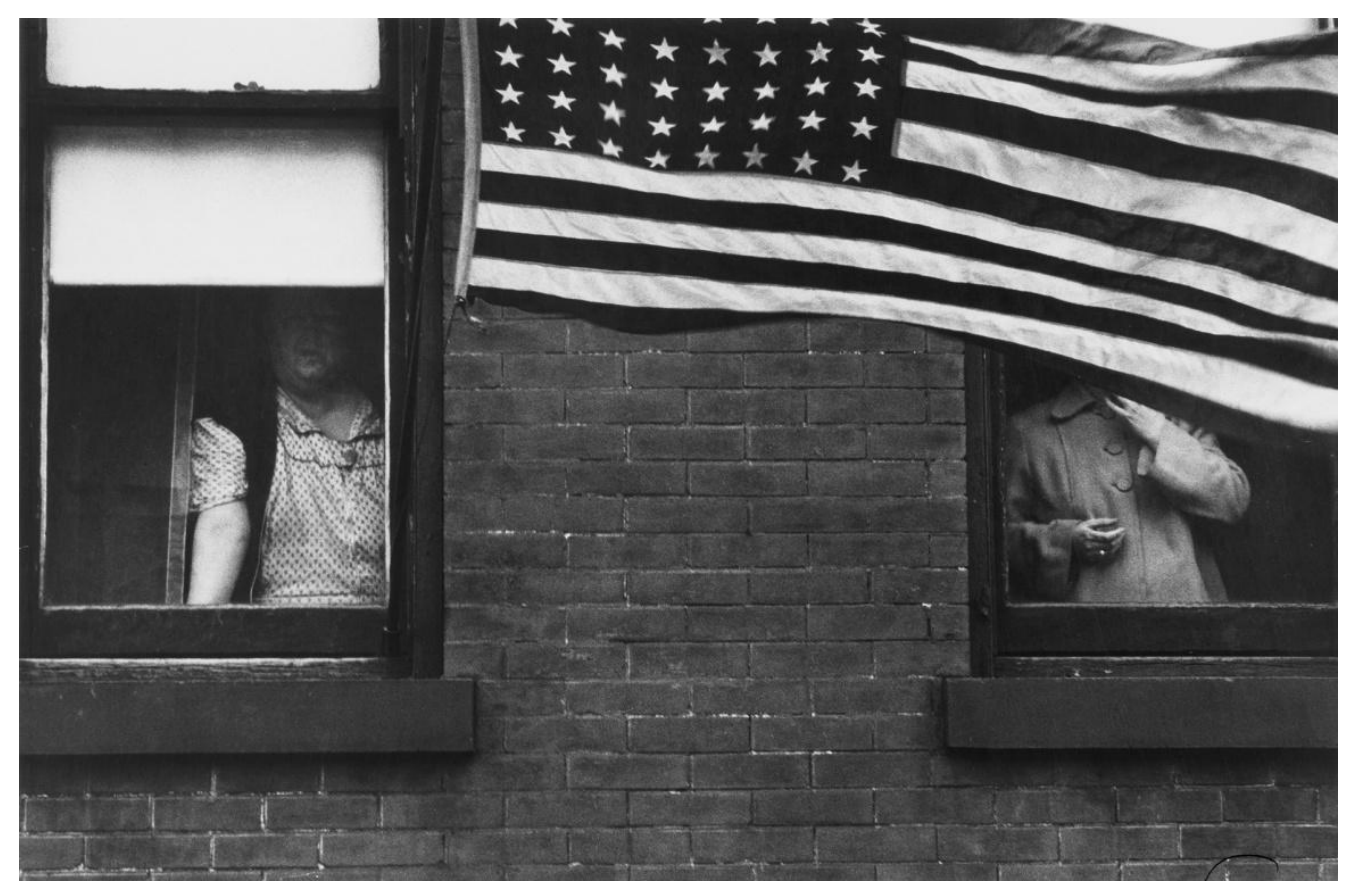

Figura 8 - "Parade—Hoboken", New Jersey (1955). @ FRANK, R.

A senhora do lado esquerdo está nas sombras e expressa certa infelicidade, que também pode significar uma sensação de ansiedade. Já a expressão da vizinha do lado direito está perdida, em virtude da bandeira dos EUA. Além da bandeira negar à fotografia uma das funções básicas (a expressão da pessoa retratada), também se torna uma ameaça. A mulher é decapitada pelo símbolo maior da nação, imagem que pode ter duas interpretações. Pode significar o ato de dar a vida pelo país - que não parece ser o que Frank queria passar para o espectador, considerando o conjunto de sua obra - ou a perda da individualidade, em virtude de uma pátria que prima por ser "o número um" do mundo.

Parade--Hoboken, New Jersey é a primeira imagem a ilustrar o livro The Americans e uma das mais poderosas de Frank, pois mostra tristeza e ambigüidade, não somente do povo americano, mas do fotógrafo. Como Mascaro (2008: 177) comenta: “As imagens The Americans não pretendem apresentar um ponto de vista distanciado, [...]; ao contrário, suas imagens se utilizam de acontecimentos externos para expressar também conflitos internos e existenciais do fotógrafo".

A profundidade do trabalho de Frank foi imortalizada também pelo fato das imagens serem em preto e branco. O preto, que remete ao desespero, morte, dinheiro, materialismo e solidão, representados por paisagens desertas, funerais e banqueiros. Enquanto que o branco, cor que expressa serenidade e esperança, contrasta com o vazio capturado pelo fotógrafo.

Iluminuras, Porto Alegre, v. 15, n. 35, p. 368-387, jan./jul. 2014 
Alberto Manguel (2001), em seu livro Lendo Imagens, chega a analisar a obra de arte de Aleijadinho como subversão. E mesmo levando em consideração as enormes diferenças entre Robert Frank e o artista barroco, ambos trabalharam com a ideia do subverter, principalmente no que concerne a valores sociais. Aleijadinho esculpia imagens de santos, trabalho atrelado a uma cultura europeia, mas com correntes ocultas de significado, que pertenciam às tradições negras da África, o inverso do que exigia a política do branqueamento na época (Manguel, 2001: 240).

Robert Frank subverteu a imagem de uma América feliz e unificada quando lançou The Americans. E como Théodore Jouffroy afirma "somente o invisível nos comove" (Manguel, 2001: 222), foi justamente a apatia, a solidão, a falta de individualismo - o que não pode se materializar - que o fotógrafo conseguiu capturar. Até mesmo em imagens de pessoas com os rostos cobertos, Frank consegue passar a sensação de vazio, de desilusão.

\section{Considerações finais ${ }^{4}$}

Sabemos que "Toda fotografia (ampliada, cortada, tirada de determinado ângulo, iluminada de certa forma) cita a realidade de maneira deturpada" (Manguel, 2001: 99), ou seja, sob o ponto de vista de quem a realiza, sendo consciente ou não. $\mathrm{O}$ índice, o não visto na obra de Frank, adquire significado se visto a partir do contexto histórico. Suas composições, enquadramentos, iluminações, mostram ao mundo justamente a sua visão da realidade norte americana, diferente daquela do American Way of Life. "Os fotógrafos não podem criar uma posição moral, mas podem reforçar uma posição já existente" (Manguel, 2001: 99).

Realizando três linhas de análise diferentes, chegamos aos mesmos lugares identitários: problemas sociais, patriotismo cego, alienação, solidão, indivíduo versus massa, a cultura do carro e da autoestrada. Símbolos do otimismo, idealismo e superioridade do American Dream no The Americans transmitem solidão, individualismo, consumismo, abandono e tristeza. Essa perspectiva dos Estados Unidos não existia na época, por isso o trabalho fora considerado ruim até o momento em que se enxerga o outro lado do American Dream, o que justifica a importância e o legado de

\footnotetext{
${ }^{4}$ Nota de agradecimento: Ao Prof. Dr. José Carlos Fernandes (UFPR) e jornalista da Gazeta do Povo (Curitiba-PR) pelas leituras e aulas na Especialização em Comunicação, Cultura e Arte (PUC-PR): foi neste espaço que o artigo foi criado, apresentado e compartilhado com os colegas.
} 
Robert e a sua influência em outros artistas. Como afirma Luciano Trigo em A Grande Feira: "Cada época cria uma arte que lhe é própria e que nunca renascerá" (Trigo, 2009).

Por outro lado, as possibilidades imagéticas de suas fotografias permitem outras interpretações, mantendo a obra aberta para novas leituras. A partir dessa possibilidade, uma nova abordagem de interpretação, a ser aprofundada e pesquisada num próximo momento, buscando estudar as hipóteses em relação à intenção de Frank, conflui nessa multiplicidade de olhares sobre a sua obra. Uma das questões a se pensar é se ele viu objetivamente a América como retratou em The Americans; se as características apontadas em sua obra foram percebidas e retratadas inconscientemente ou ainda a possibilidade de não haver nenhum engajamento e sim mais dos conflitos e inquietações do próprio artista.

As mídias como processos culturais e comunicacionais criam seus moldes e sistemas considerados aqui como elementos de importância na produção de sentido e (re)construção social midiatizada. $\mathrm{Na}$ atualidade, apresenta-se paralelamente à globalização econômica a existência de uma globalização de práticas sociais, num contexto atravessado por diferentes mídias que se entrelaçam configurando um complexo cenário midiatizado. Nesse conjunto de acontecimentos, ganham força os movimentos/fluxos de sujeitos pela experiência da miscigenação cultural, da diferença através da qual estabelecem uma linha de jogo entre duas forças: uma que empurra e outra que puxa. Assim, visualizar o espaço da diferença a partir do olhar estrangeiro de Robert Frank possibilita compreender uma mediação sociocultural que não se limita apenas ao ato de fotografar, mas que se estende às formas de leitura de suas imagens.

\section{Referências}

DAY, Jonathan. Robert Frank's "The Americans": the art of the documentary photography. Chicago, USA: The University Chicago Press, 2011.

DUBOIS, Philippe. O ato fotográfico. Campinas, SP: Papirus, 1994.

DYER, Geoff. $O$ instante contínuo: uma história particular da fotografia. (trad. Donaldson M. Garschagen). São Paulo: Companhia das Letras, 2008.

GARNER, Gretchen. Disappearing witness: change in twentieth-century American photography. Baltimore, USA: Johns Hopkins University Press, 2003. 
INGLEDEW, John. Photography. London, UK: Laurence King Publishing/St. Martins College of Arts and Design. 2005.

LEIBOVITZ, Annie. Annie Leibovitz at work. New York, USA: Random House, 2008.

LEWIN, Matt. On Robert Frank's 'Parade - Hoboken, New Jersey' (1955). Disponível em: http://towardsamagazine.wordpress.com/2010/01/06/124/>. Acesso em: 27 set. 2012.

MANGUEL, Alberto. Lendo imagens: uma história de amor e ódio. (trad. R. Figueiredo, R. Eichemberg, C. Strauch). São Paulo: Companhia das Letras, 2001.

MARTÍN-BARBERO, Jesús. Dos meios às mediações: comunicação, cultura e hegemonia. Trad. Ronald Polito; Sérgio Alcides. Rio de Janeiro: UFRJ, 2009.

MASCARO, Cristiano. Bar, New York City, 1955-6. In: MAMMI, Lorenzo; SCHWARCZ, Lilia M. (org.) $8 x$ Fotografia: ensaios. São Paulo: Companhia das Letras, 2008.

ORVELL, Miles. American photography. Oxford, UK: Oxford University Press, 2003.

PERL, Jed. New Art City: Nova York, capital da arte moderna. (trad. de Vera Pereira, Pedro M. Soares). São Paulo: Companhia das Letras, 2008.

PERLOFF, Marjorie. Poetry 1956: A Step Away From Them. Disponível em: <http://wings.buffalo.edu/epc/authors/perloff/1956.html>. Acesso em: 27 set. 2012.

WELLS, Liz (ed.). Photography: a critical introduction. London, UK: Routledg, 2004, $3^{\mathrm{a}}$ ed. 